\title{
EFEITO DA APLICAÇÃO DE Brevibacterium linens NA MATURAÇÃO DE QUEIJOS TIPO SAINT PAULIN DE CASCA TRATADA
}

\section{Effect of Brevibacterium linens on ripening of Saint Paulin type cheese washed rind}

\begin{abstract}
Renata Golin Bueno Costal, Denise Sobral ${ }^{*}$, Junio César Jacinto de Paula ${ }^{l}$,

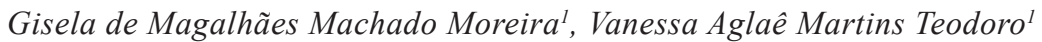

\section{RESUMO}

Brevibacterium linens (B. linens) são predominantes na casca de queijos como Gruyère, Limburgo, Reblochon, Port du Salut e Saint Paulin. No entanto, o queijo tipo Saint Paulin fabricado no Brasil, não possui a casca tratada com bactérias e sim, apenas com uma solução salina e corante urucum, o que o deixa com sabor mais suave do que as variedades européias. O objetivo deste trabalho foi avaliar a influência da utilização da Brevibacterium linens na maturação de queijos tipo Saint Paulin. Os queijos foram produzidos utilizando-se três diferentes tratamentos: controle, sem adição de $B$. linens, com aplicação de $B$. linens na casca do queijo por esfregaço e com $B$. linens adicionada ao leite destinado à fabricação dos queijos. Índices de proteólise e $\mathrm{pH}$ (próximo a casca e no centro do queijo) foram avaliados durante a maturação, nos tempos 1, 15, 30 e 54 dias, e a composição centesimal foi avaliada no dia 1 de maturação, em três repetições. A análise de $\mathrm{pH}$ e de composição centesimal, não indicou diferença significativa $(\mathrm{p}>0,05)$ entre os tratamentos. Os tratamentos com a utilização de $B$. linens apresentaram maiores índices de proteólise em relação ao tratamento controle. Assim, a utilização desse tipo de cultura adjunta $B$. linens incentiva a atividade proteolítica no queijo. Além disso, pode ser adicionada tanto no leite como na morge (solução salina) aplicada na casca do queijo.

Palavras-chave: queijo de casca tratada; proteólise; processamento; tecnologia; corineformes.

1 Empresa de Pesquisa Agropecuária de Minas Gerais (EPAMIG), Instituto de Laticínios Cândido Tostes, Rua Tenente Luiz de Freitas, 116, bairro Santa Terezinha, 36045-560, Juiz de Fora, MG, Brasil. E-mail: denisesobral@epamig.br

* Autor para correspondência. 


\begin{abstract}
Brevibacterium linens (B. linens) are predominant in the rind of cheeses such as Gruyère, Limburg, Reblochon, Port du Salut and Saint Paulin. However, the Saint Paulin type cheese manufactured in Brazil has no rind treated with bacteria but only saline solution with annatto, which leaves the cheese with softer taste than European varieties. The aim of this study was to evaluate the use of Brevibacterium linens on ripening of Saint Paulin type cheese.The cheeses were produced using three different treatments: control, no added $B$. linens, applying $B$. linens on cheese rind by smear and with $B$. linens added to the milk for cheese production. Proteolysis and $\mathrm{pH}$ were evaluated during the ripening period, at 1, 15, 30 and 54 days, and chemical composition on day 1 of ripening, in three replications. The $\mathrm{pH}$ analysis of samples collected at $2 \mathrm{~cm}$ from the lateral surface of the cheese and cheese in the center indicated no significant difference $(p>0.05)$ among treatments. There was no difference in chemical composition among treatments $(\mathrm{p}>0.05)$. Treatments with use of $B$. linens had higher rates of proteolysis in relation to the control treatment. Therefore, the use of this type of adjunct culture stimulates proteolytic activity in cheese. Furthermore, it may be added both in milk and in morge (saline solution) applied on cheese rind.
\end{abstract}

Keywords: smear ripened cheese; proteolysis; processing; technology; corineforms.

\section{INTRODUÇÃO}

O queijo Saint Paulin tem origem no queijo Port Salut, fabricado por monges trapistas da Abadia de Notre-Dame Port Du Salut construída em Entrammes, no vale do Loire, França, em 1815. Em 1874 o queijo Port Salut teve a marca registrada e por isso foi preciso adotar a denominação Saint Paulin, para que o queijo continuasse sendo fabricado em todo o mundo (MUIR, 2012). O queijo tipo Saint Paulin é um queijo maturado, semi-duro, de coloração próxima ao branco a amarelo. Fabricado com leite de vaca, búfala ou ambos, possui textura firme, porém, flexível, geralmente sem olhaduras formadas por gás. Pode ser submetido a condições alternativas durante a maturação, incluindo a adição de enzimas, desde que mantenha suas propriedades físicas, bioquímicas e sensoriais (CODEX ALIMENTARIUS, 2006). Possui sabor suave, sem acidez e sua casca fina e amarelada se forma por meio de tratamento com água, salmoura e pequena dose de urucum. Opcionalmente, microrganismos como Brevibacterium linens (FURTADO; LOURENÇO NETO,1994) podem ser utilizados durante a maturação, permitindo o desenvolvimento de características específicas dos queijos de casca tratada (BRENNAN et al., 2004).

Os queijos de casca tratada com bactérias, como o Saint Paulin, consistem em uma variedade na qual em sua superfície se desenvolve uma microbiota complexa de bactérias Gram positivas (Mc SWEENEY, 2007) oriundas do leite cru (Mc SWEENEY, 2004), da salmoura, do ar, das prateleiras da câmara de maturação ou da pele humana (BOCKELMANN et al., 2007). Brevibacterium linens foi isolada das mãos dos colaboradores e da salmoura, sendo estes fontes dessa bactéria em queijos Reblochon, Tilsit e Limburger (MOUNIER et al., 2006). 
Tradicionalmente a inoculação de bactérias no queijo é feita por um esfregaço na casca, com solução salina, iniciando pelos queijos mais maturados até os novos (WILLIAMS et al., 2004). A maturação ocorre de fora para dentro do queijo, proporcionando aroma característico e elevados níveis de proteólise e lipólise, principalmente em sua parte externa (Mc SWEENEY, 2004). B. linens está presente em uma grande variedade de queijos curados e possui enzimas proteolíticas, peptidolíticas, esterolíticas e lipolíticas que influenciam diretamente na maturação (RATTRAY; FOX, 1999). Desta forma, sua multiplicação na superfície destes queijos é essencial para formação de textura, aroma e sabor e da coloração laranja da casca (DENIS; IRLINGER, 2008). Além disso, algumas estirpes de $B$. linens são produtoras de substâncias inibidoras de L. monocytogenes (MOTTA; BRANDELLI, 2008).

Queijos de casca lavada dependem do crescimento na sua superfície de bactérias e leveduras (GOERGES et al., 2008). Leveduras que se desenvolvem na superfície de queijos recém fabricados normalmente elevam seu $\mathrm{pH}$, gerando um gradiente de acidez (Mc SWEENEY, 2004). O aumento do pH é um fator crítico na maturação, pois a $B$. linens inicia sua multiplicação em valores entre 5,6 (FURTADO, 2007) e 5,8 (FOX,1993).

Como pode ser observado, B. linens é um microrganismo de grande interesse na indústria de lácteos e ainda são necessárias muitas pesquisas para elucidar o papel preciso dessa bactéria na superfície do queijo (RATTRAY; FOX, 1999). No Brasil, os tradicionais queijos de casca lavada são fabricados sem a utilização da $B$. linens. A casca desses queijos é tratada com uma solução de sal e corante de urucum, para obter a coloração alaranjada típica proveniente do metabolismo da $B$. linens e outras bactérias corineformes. Neste contexto, o objetivo deste trabalho foi avaliar a influência da utilização da Brevibacterium linens na maturação de queijos tipo Saint Paulin submetidos a três tratamentos: queijos de casca tratada com aplicação, por esfregaço, de $B$. linens na casca do queijo; com adição de $B$. linens ao leite destinado à fabricação dos queijos e sem adição da bactéria (controle).

\section{MATERIAL E MÉTODOS}

\section{Fabricação do queijo tipo Saint Paulin}

Queijos tipo Saint Paulin de $1 \mathrm{~kg}$ foram fabricados com a utilização de $100 \mathrm{~L}$ de leite tratado termicamente $\left(65^{\circ} \mathrm{C} / 30 \mathrm{~min}\right.$. $)$ e padronizado com $3,2 \%$ gordura, para cada processo. Os tratamentos realizados foram: controle - sem adição de $B$. linens, adição de $B$. linens aplicado diretamente por meio de esfregaço na casca do queijo e outro com inoculação de $B$. linens no leite, antes da coagulação. Para ambos os tratamentos, foi adicionado ao leite a $34{ }^{\circ} \mathrm{C}$ a solução de $50 \%$ de cloreto de cálcio $(200 \mathrm{mg} / \mathrm{kg})$, corante de urucum $(0,5 \% \mathrm{v} / \mathrm{v})$, seguido da adição de $0,5 \%$ de fermento mesofílico (Lactococcus lactis ssp. lactis e Lactococcus lactis ssp. cremoris; R704; Chr. Hansen Brasil) e coagulante 100\% quimosina (Chr. Hansen, Brasil).

Em um dos tratamentos, antes da adição do coagulante, foi adicionado ao leite $1 \%$ de fermento liofilizado contendo $B$. linens (Lyofast CLO, Clerici-Sacco, Caglifio Clerici, Brasil). A coalhada foi cortada após 40 minutos de coagulação, em cubos de $0,5 \mathrm{~cm}$ de aresta e submetidos à agitação lenta durante $20 \mathrm{~min}$. Posteriormente, foi realizada a remoção de $50 \%$ do soro e o aquecimento da coalhada a $38{ }^{\circ} \mathrm{C}$ com adição de água quente $\left(45^{\circ} \mathrm{C}\right)$ na mesa proporção para aumentar a temperatura $1{ }^{\circ} \mathrm{C}$ a cada $3 \mathrm{~min}$. Após o aquecimento e mexedura, a coalhada foi pré-prensada com o dobro do peso da massa. Todo o soro foi drenado, e a coalhada foi cortada e colocada em formas cilíndricas $(1 \mathrm{~kg}$ ) e prensada em temperatura ambiente com as sucessivas 
viragens $(0,1 \mathrm{MPa} / 30$ min.;0,1 $\mathrm{MPa} / 45 \mathrm{~min}$; $0,24 \mathrm{MPa} / 90 \mathrm{~min}$; e $0,31 \mathrm{MPa} / 15 \mathrm{~min})$. Os queijos foram salgados em salmoura $(20 \%$ de $\mathrm{NaCl} \mathrm{m} / \mathrm{v}, 10{ }^{\circ} \mathrm{C}$ a $12{ }^{\circ} \mathrm{C}$ ) por 10 horas. Em seguida, os queijos foram levados para a câmara de maturação a $10{ }^{\circ} \mathrm{C}-12{ }^{\circ} \mathrm{C}$ por 25 dias. Durante esse período, os queijos foram virados diariamente e tratados a cada três dias com uma solução salina, aplicada de acordo com cada tratamento proposto.

No queijo fabricado sem adição de $B$. linens, a casca foi tratada com uma solução de água, sal $(10 \% \mathrm{~m} / \mathrm{v})$ e corante de urucum $(5 \% \mathrm{v} / \mathrm{v})$. No segundo tratamento a casca do queijo foi tratada com uma solução de água, sal $(10 \% \mathrm{~m} / \mathrm{v})$ e $B$. linens $(1 \%$ Lyofast CLO, Clerici-Sacco, Caglifio Clerici, Brasil). No queijo fabricado com adição de $B$. linens no leite, a solução passada na casca continha água e sal $(10 \% \mathrm{~m} / \mathrm{v})$. Os queijos foram maturados a $10-12{ }^{\circ} \mathrm{C}$ com umidade relativa do ar acima de $95 \%$. Após os 25 dias, os queijos foram secos em câmara de secagem $\left(10^{\circ} \mathrm{C}\right.$ - $12{ }^{\circ} \mathrm{C}$ ) por 3 dias e embalados em embalagem termoencolhível a vácuo e mantidos em câmara fria a $10-12{ }^{\circ} \mathrm{C}$. O experimento foi repetido três vezes e os queijos foram analisados em 4 tempos de maturação (1, 15,30 e 54 dias).

\section{Análises físico-químicas}

As amostras dos queijos tipo Saint Paulin foram analisadas quanto a teores percentuais $(\mathrm{m} / \mathrm{m})$ de umidade e sólidos totais (BRASIL, 2006); teor percentual $(\mathrm{m} / \mathrm{m})$ de gordura: método butirométrico (BRASIL, 2006); porcentagem de nitrogênio total (NT), nitrogênio solúvel em $\mathrm{pH} 4,6\left(\mathrm{NS}_{\mathrm{pH} 4,6}\right)$ e em tricloroacético (TCA) a $12 \%\left(\mathrm{NS}_{\mathrm{TCA} 12 \%}\right)$, conforme descrito por Gripon et al. (1975), sendo as frações nitrogenadas determinadas pelo método de Kjeldahl (IDF 20:B, (1993)), para cálculo dos índices de proteólise: $\% \mathrm{NS}_{\mathrm{pH} 4,6} / \mathrm{NT}$ (extensão da proteólise) e $\% \mathrm{NS}_{\mathrm{TCA} 12 \%} / \mathrm{NT}$ (profundidade da proteólise)
(WOLFSHOON-POMBO; LIMA, 1989); teor percentual $(\mathrm{m} / \mathrm{m})$ de proteína: com base no teor de nitrogênio total, o fator utilizado de conversão de nitrogênio em proteína foi 6,38 .

O processo de preparo de amostra foi realizado segundo Brasil (2006). O pH foi determinado conforme descrito em Bradley et al. (1992) utilizando-se equipamento Tecnal modelo Tec-2 (Tecnal, Piracicaba, SP, Brasil), a $20-25^{\circ} \mathrm{C}$, coletando-se amostras em duas porções do queijo, a $2 \mathrm{~cm}$ da superfície lateral e no centro da peça. As análises de $\mathrm{pH}$, extensão e profundidade da proteólise foram realizadas em triplicata, ao longo do período de maturação, nos dias 1, 15, 30 e 54, em 3 repetições.As análises de composição centesimal dos queijos foram realizadas no dia 1 de maturação. Os resultados obtidos foram analisados por programa estatístico apropriado “MINITAB”, versão 14 (2003).

\section{RESULTADOS E DISCUSSÃO}

O teor de umidade, proteína total e gordura no extrato seco não foram diferentes entre os tratamentos $(\mathrm{p}>0,05)$ (Tabela 1). Os queijos podem ser classificados como de alta umidade, devido ao teor de umidade apresentar-se entre 46,0-54,9\%. São classificados como gordo, devido a gordura no extrato seco (GES) estar entre 45,0-59,9 \% (BRASIL, 1996).

Os diferentes tratamentos não influenciaram na composição centesimal dos queijos. Este resultado já era esperado, visto que os diferentes tratamentos propostos, não influenciam na tecnologia de fabricação, no que diz respeito à cifra de transição dos constituintes de leite.

Quanto ao pH (Tabela 2), não houve diferença significativa entre os tratamentos $(p>0,05)$ e tempos de maturação $(p>0,05)$ dos queijos. A interação entre os dois fatores (tratamentos e tempo de maturação) também não foi significativa $(\mathrm{p}>0,05)$. Em todos 
os tratamentos, aos 54 dias de maturação, os valores de $\mathrm{pH}$ apresentaram médias condizentes ao descrito por Furtado; Lourenço Neto (1994).

Os valores de $\mathrm{pH}$ dos queijos dos três tratamentos com 1 dia de fabricação são semelhantes ao $\mathrm{pH}(5,22 \pm 1,15)$ encontrado por Boulares et al. (2011) para queijos tipo Saint Paulin oriundos de leite não pasteurizado, com 2 dias de maturação. $\mathrm{O}$ pH dos queijos de casca tratada varia em função da microbiota predominante. Fungos filamentosos e leveduras se desenvolvem durante as fases iniciais de maturação, provocam a desacidificação da superfície do queijo, permitindo a multiplicação de bactérias e o aumento de sua atividade enzimática (BRENNAN et al., 2004). Essa desacidificação é dependente da quantidade e das cepas de leveduras presentes (Mc SWEENEY, 2007). No caso dos queijos fabricados nesse trabalho, não foram adicionadas leveduras e fungos, que foram provenientes do próprio leite e de contaminações do ambiente.

A elevação do $\mathrm{pH}$ se faz necessária para o desenvolvimento da $B$. linens (Mc SWEENEY, 2004), que pode ser verificado pela alteração da cor da casca (que muda da cor amarelo claro para a cor laranja) e pela elevação da proteólise no queijo que foi fabricado com adição da B. linens (BRENNAN et al., 2004).

Tabela 1 - Composição centesimal média $(\% \mathrm{~m} / \mathrm{m})$ de queijo Saint Paulin com um dia de maturação $(\mathrm{n}=3)^{*}$

\begin{tabular}{cccc}
\hline Tratamentos & $\begin{array}{c}\text { Umidade } \\
\% \mathrm{~m} / \mathrm{m}\end{array}$ & $\begin{array}{c}\text { Proteína total } \\
\% \mathrm{~m} / \mathrm{m}\end{array}$ & $\begin{array}{c}\text { Gordura no } \\
\text { Extrato Seco } \\
\% \mathrm{~m} / \mathrm{m}\end{array}$ \\
\hline Sem $B$. linens (controle) & $50,48^{\mathrm{a}}$ & $22,58^{\mathrm{a}}$ & $47,99^{\mathrm{a}}$ \\
B. linens adicionada na casca & $50,54^{\mathrm{a}}$ & $22,73^{\mathrm{a}}$ & $49,15^{\mathrm{a}}$ \\
B. linens adicionada no leite & $50,16^{\mathrm{a}}$ & $22,59^{\mathrm{a}}$ & $47,82^{\mathrm{a}}$ \\
\hline
\end{tabular}

* Letras iguais não diferem significativamente pelo teste de Tukey ao nível de 5\% de probabilidade.

Tabela 2 - Valores médios de pH para os respectivos dias de maturação e tratamentos, aferidos a $2 \mathrm{~cm}$ da superfície lateral e no centro do queijo tipo Saint Paulin

\begin{tabular}{c|c|c|c|c|c|c|c|c}
\hline \multirow{2}{*}{} & \multicolumn{3}{|c|}{$\begin{array}{c}\text { Média de pH a } 2 \mathrm{~cm} \text { da superfície lateral } \\
\text { Período de maturação (dias) }\end{array}$} & \multicolumn{4}{c}{$\begin{array}{c}\text { Média de pH no centro do queijo } \\
\text { Período de maturação (dias) }\end{array}$} \\
\cline { 2 - 8 } & 01 & 15 & 30 & 54 & 01 & 15 & 30 & 54 \\
\hline $\begin{array}{c}\text { Sem } \\
\begin{array}{c}\text { B. Linens } \\
\text { controle) }\end{array}\end{array}$ & $5,42 \pm 0,61$ & $5,34 \pm 0,61$ & $5,30 \pm 0,54$ & $5,28 \pm 0,22$ & $5,42 \pm 0,61$ & $5,20 \pm 0,43$ & $5,15 \pm 0,31$ & $5,28 \pm 0,22$ \\
\hline $\begin{array}{c}\text { B. Linens } \\
\text { adicionada } \\
\text { na casca }\end{array}$ & $5,35 \pm 0,51$ & $5,03 \pm 0,14$ & $5,32 \pm 0,18$ & $5,31 \pm 0,15$ & $5,35 \pm 0,51$ & $5,03 \pm 0,17$ & $5,06 \pm 0,05$ & $5,31 \pm 0,15$ \\
\hline $\begin{array}{c}\text { B. Linens } \\
\text { adicionada } \\
\text { no leite }\end{array}$ & $5,35 \pm 0,51$ & $5,00 \pm 0,08$ & $5,35 \pm 0,23$ & $5,50 \pm 0,26$ & $5,35 \pm 0,51$ & $5,04 \pm 0,08$ & $5,09 \pm 0,15$ & $5,49 \pm 0,26$ \\
\hline
\end{tabular}


A análise de variância para \% $\mathrm{NS}_{\mathrm{pH} 46} / \mathrm{NT}$ indicou efeito significativo $(\mathrm{p} \leq 0,05)$ para tratamento, tempo de maturação e interação entre tratamento e tempo (Tabela 3). Os valores médios das amostras dos queijos dos tratamentos B e C, não diferiram entre si ( $\mathrm{p}$ $>0,05)$, mas superaram significativamente $o$ do tratamento $\mathrm{A}$, o que indica que a proteólise foi maior nos tratamentos com $B$. linens do que no controle.

Tabela 3 - Resultados médios para \% $\mathrm{NS}_{\mathrm{pH} 4,6} /$ NT em todos os tempos dos queijos tipo Saint Paulin conforme o tratamento dos queijos $(\mathrm{n}=3)$

\begin{tabular}{lc}
\hline \multicolumn{1}{c}{ Tratamentos } & $\% \mathrm{NS}_{\mathrm{pH} 4,6} / \mathrm{NT}^{*}$ \\
\hline Sem B. linens (controle) & $9,76^{\mathrm{b}}$ \\
B. linens adicionada na casca & $13,91^{\mathrm{a}}$ \\
B. linens adicionada no leite & $14,24^{\mathrm{a}}$ \\
\hline
\end{tabular}

* Letras iguais não diferem significativamente pelo teste de Tukey ao nível de 5\% de probabilidade.

A relação das médias encontradas para $\% \mathrm{NS}_{\mathrm{pH}}{ }_{4,6} / \mathrm{NT}$ dos diferentes tratamentos ao longo do período de maturação estão apresentadas na Figura 1. No desdobramento da interação entre os fatores, quando se estudou os tratamentos em cada tempo de maturação, não houve diferenças significativas dos tratamentos nos tempos 1 e 15 dias ( $p>0,05)$. Aos 30 e 54 dias de maturação, os tratamentos B e $\mathrm{C}$ não diferiram entre si, mas apresentaram proteólise superior às do tipo $\mathrm{A}(\mathrm{p} \leq 0,05)$, conforme demonstrado na Figura 1.

O teor de umidade foi semelhante entre os queijos, e, portanto não influenciou na proteólise, o que torna evidente a influência das enzimas proteolíticas da $B$. linens na proteólise. Segundo Bockelmann et al. (2007) as bactérias corineformes típicas dos queijos de casca lavada são verificadas em altas contagens, após duas semanas de maturação, e altas contagens de Brevibacterium linens são observadas em queijos maturados por longos períodos, o que pode justificar a diferença na proteólise após 30 dias de maturação do presente estudo. Leclercq-Perlat et al. (2000) observaram um aumento exponencial do percentual de $\mathrm{NS}_{\mathrm{pH} 4,6} / \mathrm{NT}$ ao longo da maturação, quando avaliaram a multiplicação de Debaryomyces hansenii e $B$. linens em um queijo macio feito em condições assépticas.

A análise de variância para $\% \mathrm{NS}_{\mathrm{TCA} 12 \%} /$ NT indicou efeito significativo $(\mathrm{p} \leq 0,05)$

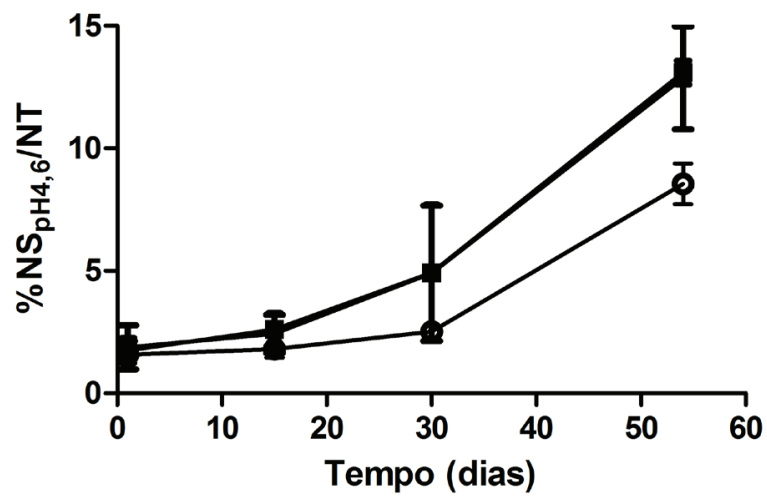

Figura 1 - Resultados médios para $\% \mathrm{NS}_{\mathrm{pH} 4,6} / \mathrm{NT}$ dos queijos tipo Saint Paulin conforme o tempo de maturação e o tratamento. (O) Tratamento A- sem B. linens (controle); ( $\mathbf{\Delta}$ ) Tratamento B- $B$. linens; $(\square)$ Tratamento C- B. linens no leite 
para tratamentos e tempos de maturação, mas este efeito não foi detectado para a interação entre os dois fatores $(p>0,05)$. As médias de $\% \mathrm{NS}_{\text {TCA } 12 \%} / \mathrm{NT}$ dos queijos com diferentes tratamentos estão demonstrados na Tabela 4. Os queijos dos tratamentos B e $\mathrm{C}$ não apresentaram diferença significativa ( $p>0,05)$ entre si, mas ambos superaram os queijos do tratamento A (Tabela 4), indicando que os percentuais de $\mathrm{NS}_{\mathrm{TCA} 12 \%} / \mathrm{NT}$ da proteólise apresentaram-se maiores nos tratamentos com B. linens que no controle.

Tabela 4 - Resultados médios para \% $\mathrm{NS}_{\text {TCA } 12 \%} / \mathrm{NT}$ em todos os tempos dos queijos tipo Saint Paulin conforme o tratamento dos queijos $(\mathrm{n}=3)$

\begin{tabular}{lc}
\hline \multicolumn{1}{c}{ Tratamentos } & $\% \mathrm{NS}_{\mathrm{TCA} 12 \%} / \mathrm{NT}^{*}$ \\
\hline Sem B. linens (controle) & $3,60^{\mathrm{a}}$ \\
B. linens adicionada na casca & $5,52^{\mathrm{b}}$ \\
B. linens adicionada no leite & $5,59^{\mathrm{b}}$ \\
\hline
\end{tabular}

* Médias seguidas pelas mesmas letras não diferem estatisticamente $(\mathrm{P}>0,05)$ entre os tratamentos.

A relação das médias encontradas para $\% \mathrm{NS}_{\mathrm{TCA} 12 \%} / \mathrm{NT}$ dos diferentes tratamentos ao longo do período de maturação estão apresentadas na Figura 2. O teor de nitrogênio solúvel em TCA $12 \%$ dos queijos foi influenciado principalmente pelas enzimas do fermento acidificante mesofílico e da bactéria (B. linens) utilizados neste experimento. A análise de nitrogênio solúvel foi realizada tomando a amostra do queijo como um todo, portanto, não foi possível verificar se na superfície do queijo tratados $\operatorname{com} B$. linens houve maior índice proteólise quando comparado ao centro do queijo, visto que essa bactéria se desenvolve apenas na superfície. No entanto, observou-se um maior $\% \mathrm{NS}_{\mathrm{TCA} 12 \%} / \mathrm{NT}$ ao longo de todo o período de maturação para os queijos no qual a $B$. linens foi adicionada, seja no leite ou por esfregaço na casca, devido as suas enzimas peptidolíticas.

Verificou-se também que quanto maior o tempo de maturação, maior foi a diferença do percentual de $\mathrm{NS}_{\mathrm{TCA} 12 \%} / \mathrm{NT}$ dos queijos tipo Saint Paulin tratados com $B$. linens se comparados ao queijo controle. Estas diferenças podem ser explicadas, pois microrganismos como $B$. linens, se multiplicam na superfície de queijos de casca tratada, sintetizam enzimas proteolíticas e

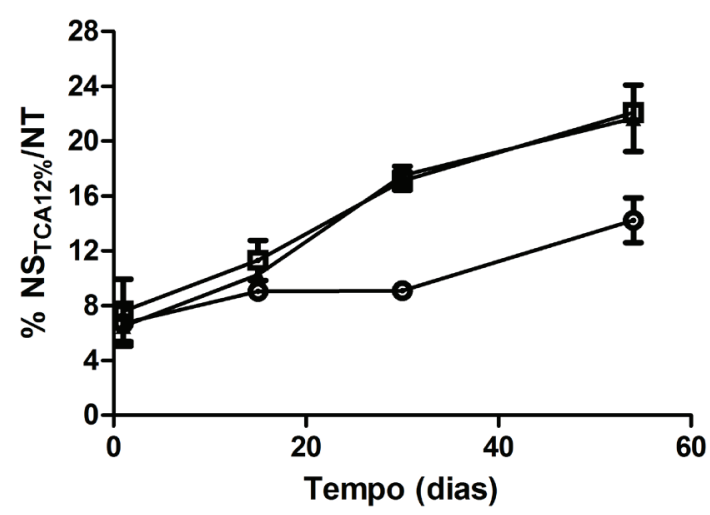

Figura 2 - Resultados médios para \% $\mathrm{NS}_{\mathrm{TCA} 12 \%} / \mathrm{NT}$ dos queijos tipo Saint Paulin conforme o tempo de maturação e o tratamento. (O) Tratamento A- sem B. linens (controle); ( $\mathbf{\Delta})$ Tratamento B- B. linens; ( $\square$ ) Tratamento C- B. linens no leite 
lipolíticas mais ativas que as das bactérias provenientes do fermento ou mesmo de contaminantes (REPS, 1993), interferindo na maturação do queijo. Segundo Gobetti et al. (1997), ocorre extensa proteólise durante a maturação de queijos de casca lavada, por um período de 40 a 50 dias.

\section{CONCLUSÕES}

Os resultados deste estudo demonstraram que $B$. linens se desenvolveu nos queijos, independente da forma de aplicação na casca ou adicionada ao leite. A B. linens influenciou na proteólise e pode ser aplicada nos queijos de casca tratada com esse propósito. Pesquisas complementares a este estudo, com a utilização de $B$. linens em queijos, devem ser realizadas com objetivo de avaliar características de textura, cor, sabor e, principalmente, aceitação sensorial desses queijos.

\section{REFERÊNCIAS}

BRASIL. Ministério da Agricultura, Pecuária e Abastecimento. Instrução Normativa $\mathrm{n}^{\mathrm{o}} 68$, de 12 de dezembro de 2006. Oficializa os métodos analíticos oficiais físicoquímicos, para controle de leite e produtos lácteos. Diário Oficial da Republica Federativa do Brasil, Brasília, 14 dez. 2006. Seção 1, p. 8.

BRASIL. Ministério da Agricultura, Pecuária e Abastecimento. Portaria $n^{\circ} 146$ de 07 de março de 1996. Aprovar os Regulamentos Técnicos de Identidade e Qualidade dos Produtos Lácteos. Diário Oficial da República Federativa do Brasil, Brasília, 11 mar. 1996. Seção 1, p. 3977.

BOCKELMANN, W. et al Application of a defined surface culture for ripening of Tilsit cheese. Kieler Milchwirtschaftliche
Forschungsberichte, v. 59, n. 3, p. 191-202, 2007.

B OULARES, M.; MANKAI, M.; HASSOUNA, M. Effect of activating lactoperoxidase system in cheese milk on the quality of Saint-Paulin cheese. International Journal of Dairy Technology, v. 64, n. 1, p. 75-83, 2011.

BRADLEY JUNIOR, R. L. et al. Chemical and Physical Methods. In: MARSHALL, R. T. (Ed.) Standard Methods for the Examination of Dairy Products. 16th ed. 1992. Washington: American Public Health Association (APHA), 1992. cap. 15, p. 433-531.

BRENNAN, N. M. et al. Bacterial surface ripened cheeses. In: BRENNAN, N. M. et al. Cheese: Chemistry, Physics and Microbiology. $3^{\text {rd }}$ ed. London: Chapman \& Hall, 2004. v. 2, p. 199-225.

CODEX ALIMENTARIUS. Joint Fao/Who Food standards programme. Report of the seventh session of the codex committee on milk and milk products. Geneva: Codex Alimentarius, 2006. 167p.

DENIS, C.; IRLINGER, F. Safety assessment of dairy microorganisms: Aerobic coryneform bacteria isolated from the surface of smearripened cheeses. International Journal of Food Microbiology, v. 126, n. 3, p. 311-315, 2008.

FOX, P. F. Bacterial Surface- ripened cheeses. In: FOX, P. F. Cheese: Chemistry, physics and microbiology. $2^{\text {rd }}$ ed. New York: Elsevier, 1993. v. 2, p. 137-172.

FURTADO, M. M.; LOURENÇO NETO, J. P. Tecnologia de queijos: manual técnico para a produção industrial de queijos. São Paulo: Dipemar Editora, 1994. 118p. 
FURTADO, M. M. Queijos com olhaduras. São Paulo: Fonte, 2007. 179 p.

GOERGES, S. et al. Commercial ripening starter microorganisms inoculated into cheese milk do not successfully establish themselves in the resident microbial ripening consortia of a South German red smear cheese. Applied and Environmental Microbiology, v. 74, n. 7, p. 2210-2217, 2008.

GRIPON, J. C. et al. Etude du rôle des microorganismes et des enzymes are cours de la maturation des fromages. Lait, v. 55, n. 1, p. 502-512, 1975.

INTERNATIONAL DAIRY FEDERATION. Standards 20B Milk: determination of Nitrogen Content. Brussels: IDF, 1993.

GOBETTI, M. et al. Microbiology and biochemistry of Tallegio cheese during ripening International Dairy Journal, v. 7, p. 509517, 1997.

LECLERCQ-PERLAT, M. N. et al. Behaviour of Brevibacterium linens and Debaryomyces hansenii as ripening flora in controlled production of smear soft cheese from reconstituted milk: protein degradation. Journal of Dairy Science, v. 83, n. 8, p. 1665-1673, 2000.

Mc SWEENEY, P. L. H. Cheese problems solved. Cambridge: Woodhead Publishing, 2007. 388 p.

Mc SWEENEY, P. L. H. Biochemistry of cheese ripening. International Journal of
Dairy Technology, v. 24, n. 3, p. 127-144, 2004.

MOTTA, A. S.; BRANDELLI, A. Properties and antimicrobial activity of the smear surface cheese coryneform bacterium Brevibacterium linens. European Food Research and Technology, v. 227, n. 5, p. 1299-1308, 2008.

MOUNIER, J. et al. Sources of the adventitious microflora of a smear-ripened cheese. Journal of Applied Microbiology, v. 101, n. 3, p. 668-681, 2006.

MUIR, R. Queijos de casca lavada. In: MUIR, R. 500 queijos. $1^{\mathrm{a}}$ ed. São Paulo: Marco Zero, 2012. p. 114-141.

RATTRAY, F. P.; FOX, P. F. Aspects of enzymology and biochemical properties of Brevibacterium linens relevant to cheese ripening: a review. Journal of Dairy Science, v. 82, n. 5, p. 891-909, 1999.

REPS, A. Bacterial surface-ripened cheeses. In: REPS, A. Cheese: Chemistry, Physics and Microbiology. $2^{\text {nd }}$ ed. London: Chapman \& Hall, 1993. v. 2, p. 137-172.

WILLIAMS, A. G. et al. Enzymes involved in flavour formation by bacteria isolated from the smear population of surface-ripened cheese. International Journal of Dairy Technology, v. 57, n. 1 , p. 7-13, 2004.

WOLFSHOON-POMBO, A. F.; LIMA, A. Extensão e profundidade da proteólise de queijo minas frescal. Revista do Instituto de Latícinios Cândido Tostes, v. 44, n. 261-266, p. 50-54, 1989. 